\title{
Explicit Modelling of Slag Infiltration and Shell Formation during Mould Oscillation in Continuous Casting
}

\author{
Pavel E. RAMIREZ-LOPEZ, Peter D. LEE and Kenneth C. MILLS \\ Department of Materials, Imperial College London, Prince Consort Road, London SW7 2AZ, UK. \\ (Received on September 16, 2009; accepted on December 11, 2009)
}

\begin{abstract}
A mathematical model of the continuous casting process, which explicitly incorporates the presence of slag, molten steel, heat transfer through the mould walls, and shell solidification, is presented. The model is based on the solution of the Navier-Stokes equations for the multiphase slag-steel-air system under transient conditions, including tracking of the interface between these phases. The use of an extremely fine mesh $(100 \mu \mathrm{m})$ in the meniscus region allows, for the first time, the direct calculation of liquid slag infiltration into the shell-mould gap. Elsewhere, a coarser mesh is used to capture the influence of the metal flow on the overall solution. Predictions are compared with prior, cold model experiments and high temperature mould simulators. Excellent agreement was found for features such as slag film development and heat flux variations during the oscillation cycle. Furthermore, predictions of shell thicknesses and heat fluxes for a variety of simulated casting speeds are also in good agreement with plant measurements. These findings provide an improved fundamental understanding of the basic principles involved in slag infiltration and solidification inside the mould and how these affect key process parameters, such as powder consumption and shell growth. These parameters have a decisive effect on the formation of oscillations marks and transverse cracks, which are a major source of defects in the casting practice.
\end{abstract}

KEY WORDS: slage infiltration; shell solidification; mould oscillation; continuous casting; slab casting; modelling.

\section{Introduction}

In today's steel industry, finding solutions that improve both productivity and quality can equate to survival in a competitive market. Defects are major sources of quality problems, yield loss and unnecessary energy consumption. They represent a challenging problem in the field and are a subject of extensive research. The formation of these casting defects (i.e. deep oscillation marks, transverse and longitudinal cracks, inclusions, etc.) is related to casting conditions in the plant (such as powder consumption, casting speed and mould oscillation), which are strongly inter-dependent and occur simultaneously inside the mould. For instance, oscillation marks are periodical defects formed on the slab surface due to mould oscillation but are also highly affected by slag infiltration, mould level and heat transfer conditions in the mould. ${ }^{1,2)}$

The need to predict the formation of defects has driven the development of a variety of numerical models to simulate solidification within the mould. ${ }^{3-6)}$ Nevertheless, the generalized approach for these models is based on fitting plant data, such as measurements from thermocouples (embedded in the mould walls) during the operation of the caster. These values are used to define both the heat removal rate through the mould walls and the solidification time. As expected, these models have proven reliable when the conditions under analysis are close to those used in the data acquisition. However, this approach fails when casting conditions diverge radically from conventional limits. This is the case with significant increases in casting speed or the introduction of new steel grades with poor castabilty (e.g. TRIP and TWIP steels). ${ }^{7)}$ These changes increase the number of defects and can lead to major casting problems such as breakouts and hot tearing. Finally, existing, fitted models are unable to explain the mechanisms involved in slag infiltration and initial solidification due to their complexity (e.g. Ref. 8)).

Improved numerical models and experimental techniques are required to address these issues. However, a major hindrance for an integral analysis lies in the treatment of the slag film (i.e. solid plus liquid slag layers that form between shell and mould), which controls both lubrication of the strand and thermal insulation. Small-scale laboratory experiments have been used to model these layers and provide useful information on basic interactions, e.g., the relation between powder properties and heat transfer; but fail to account for the effects of more complex phenomena such as the influence of mould oscillation and shell formation on the evolution of the slag film. ${ }^{9-11)}$

Numerical simulations suffer from similar problems since the majority of models address only a limited number of phenomena (such as the interaction of metal flow with heat transfer or heat transfer effects on solidification) but ignore the behaviour of molten slag inside the shell-mould gap. ${ }^{3,12)}$ Again, this problem has been addressed through algebraic and empirical models based on plant measure- 
ments of powder consumption rates. ${ }^{13-15)}$ However, these models provide only limited information on the conditions prevailing in the meniscus during initial solidification (where most defects arise). Furthermore, there are only a few studies where transient descriptions of this initial solidification have been attempted and they do not supply any information on the evolution of the shell as a function of intermittent changes in the metal flow. ${ }^{2,16)}$

In summary, there is a well established need for a numerical model able to couple such wide range of phenomena under transient conditions. A model which addresses many of these limitations is presented in this study, allowing both new insights into the triggering mechanisms of infiltration and solidification, which are, in turn, intimately related to the formation of defects.

\section{Model Description}

A comprehensive two dimensional model of the heat transfer, fluid flow, and solidification was developed based on a commercial code. This model calculates the flow dynamics of molten steel, air and slag within the mould, building on a prior more limited model. ${ }^{17)}$ Direct infiltration of slag into the shell-mould gap is achieved by coupling the Navier-Stokes equations for compressible viscous flow with a multiphase tracking technique known as volume of fluid $(\mathrm{VOF})^{18)}$ and a $\kappa-\varepsilon$ turbulence model. ${ }^{17,19)}$

$$
\begin{aligned}
& \frac{\partial}{\partial t}\left(\alpha_{q} \rho_{q}\right)+\nabla \cdot\left(\alpha_{q} \rho_{q} \vec{v}\right)=S_{\alpha_{q}}+\sum_{p=1}^{n}\left(\dot{m}_{p q}-\dot{m}_{q p}\right) \ldots \\
& \frac{\partial}{\partial t}\left(\rho_{\text {mix }} \vec{v}\right)+\nabla \cdot\left(\rho_{\text {mix }} \vec{v} \vec{v}\right) \\
& \quad=-\nabla p+\nabla\left[\mu_{\text {mix }}(\nabla \vec{v}+\nabla \vec{u})\right]+\rho_{\text {mix }} \beta \Delta T g+S_{\sigma} \ldots
\end{aligned}
$$

All variables are defined in the list of symbols at the end of the manuscript. Calculation of the slag-metal interface is attained through the Continuum Surface Force (CSF) model developed by Brackbill et al., ${ }^{20)}$ which is added to the momentum equation through the source term $S_{\sigma}$. For instance $S_{\sigma}$ becomes $S_{\text {steel-slag, }}$, for steel and slag at the meniscus:

$$
S_{\text {steel-slag }}=\sigma_{\text {steel-slag }} \frac{\rho_{\text {mix }} \kappa_{\text {slag }} \nabla \alpha_{\text {slag }}}{\frac{1}{2}\left(\rho_{\text {steel }}+\rho_{\text {slag }}\right)} .
$$

Previous models estimated the slag film thickness through empirical equations. ${ }^{15,21)}$ However, the present model avoids the use of additional constraints to model the meniscus, and thereby, the solid and liquid slag film thicknesses are calculated by the actual inflow of molten slag into the gap between shell and mould.

Heat flux to the mould walls is calculated as the difference between the temperature of the shell and the mould divided by the thermal resistances provided by the slag film and the contact resistance (also known as interfacial resistance):

$$
q_{\text {hor }}=\frac{T_{\text {shell }}-T_{\text {mould }}}{\left(\frac{d}{k}\right)_{\text {liquid }}+\left(\frac{d}{k}\right)_{\text {solid }}+r_{\text {int }}}
$$

It must be noted that this interfacial resistance is caused by the crystallization of the slag film, which actively increases the actual "surface roughness" and thermal resistance in the gap. ${ }^{11)}$ Boundary conditions and casting parameters employed in the simulations are presented in Fig. 1 and Table 1, respectively. A pressure inlet condition is applied at the mould top to model the effects of a system open to the atmosphere. The amount of heat extracted by the primary and secondary cooling regions is defined by a heat transfer coefficient and average heat flux as shown in Fig. 1. Heat flux through the SEN walls and any other walls other than the symmetry planes, inlets, outlets and mould water channels are assumed to be zero.

The model includes the SEN, metal and slag flow inside the mould and half a meter of slab length below the mould exit, as shown in Fig. 1. The solid domain includes the mould narrow face with the cooling system in its respective position. The total mesh size consists of 132, 276 elements

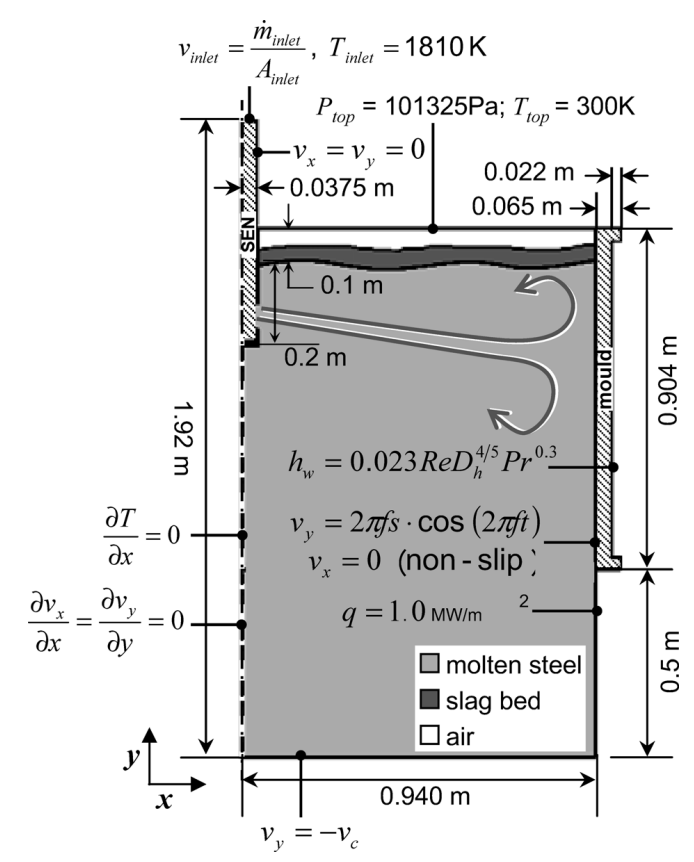

Fig. 1. Schematic illustrating model dimensions and boundary conditions.

Table 1. Material properties used in the simulations.

\begin{tabular}{c|c}
\hline \multicolumn{2}{c}{ Properties for low C steel } \\
\hline Density $\left(\mathrm{kg} / \mathrm{m}^{3}\right)$ & Ref $^{23)}$ \\
\hline Viscosity $(\mathrm{Pa}-\mathrm{s})$ & 0.006 \\
\hline Tliquidus $\left({ }^{\circ} \mathrm{K}\right)$ & 1790 \\
\hline Tsolidus ( $\left.{ }^{\circ} \mathrm{K}\right)$ & 1810 \\
\hline \multicolumn{2}{c}{ Slag Properties } \\
\hline Break Temperature $\left({ }^{\circ} \mathrm{K}\right)$ & 1350 \\
\hline $\begin{array}{c}\text { Thermal conductivity at } \\
1350 \mathrm{~K}\left(\mathrm{~W} / \mathrm{m} \cdot{ }^{\circ} \mathrm{K}\right)\end{array}$ \\
\hline Viscosity $(\mathrm{Pa}-\mathrm{s})$ & 1 \\
\hline
\end{tabular}


ranging in size from 100 to $5 \mathrm{~mm}$.

The solution procedure consists of 3 steps. The first step is to solve the metal flow under iso-thermal conditions. ${ }^{17)}$ The second step is the addition of the slag layer ${ }^{23)}$ as an initially flat $50 \mathrm{~mm}$ thick layer on top of the steel bath. Powder is added as constant flux at the upper boundary. Slag properties (viscosity and thermal conductivity) are defined as a function of temperature and composition as detailed in, ${ }^{23}$ ) which allows the calculation of a liquid pool for the slag in immediate contact with the steel (known as slag pool). This approach is analogous to that used by Meng et al. ${ }^{16)}$ and Mapelli et al., ${ }^{24)}$ where a sudden increase in viscosity occurs at the break temperature $\left(T_{b r}\right)$ of the slag; this allows the solid layer to be differentiated from the liquid slag layer through the $T_{b r}$ isotherm. This approach also produces the formation of a sintered layer, which corresponds to molten slag that has returned to solid state in colder areas of the bed. Interestingly, the model illustrates that the slag bed/pool thickness fluctuates freely, with a thicker sintered layer predicted in the mould corner, where it takes the shape of a slag rim attached to the mould wall. Thus, the solid slag layer includes 3 main sections; inside the shellmould gap, it forms a thin film that remains attached to the mould side $\left(d_{\text {solid }}\right)$. Above the shell-mould gap, the solid slag accumulates into a rim-like shape that matches the curvature of the meniscus. However, this rim is connected to the rest of the solid material in the bed located just above the liquid pool forming the sintered layer. As a consequence, the rim shape is not predefined but is a result of the calculations.

In the third step, the heat transfer is solved for a period of time which is sufficient to allow a regular solid shell to form and infiltration to occur (typically $2000 \mathrm{~s}$ using time steps of $0.005 \mathrm{~s}$ ). Total calculation time is approximately $120 \mathrm{~h}$ per case on a dual-core PC.

\section{Results and Discussion}

\subsection{Metal and Slag Flow}

Flow dynamics and heat transfer were analysed for a series of cases under the conditions listed in Table 2. Typical flow streamlines and temperature fields are shown in Fig. 2 for a casting speed $\left(v_{c}\right)$ of $0.9 \mathrm{~m} / \mathrm{min}$. A similar flow pattern was found for all casting speeds simulated, with rolls developing above and below the main discharging jet leaving the SEN, which agrees with previously reported findings. ${ }^{17)}$ The effect of changes in casting speed is also consistent with previous numerical and experimental observations, showing increases in velocity magnitude in the jet with increasing casting speed. ${ }^{19)}$ Velocities in the slag bed and at the steel-slag interface, are successfully calculated with this technique due to the multiphase approach defined by Eqs. (1)-(3). These velocity fields are critical for infiltration and local flow in the meniscus as described later.

The right hand side of Fig. 2(a) shows typical temperature distributions produced by the jet and rolls, for steel entering the SEN at a temperature of $1810 \mathrm{~K}$, with the jet retaining most of its heat until the impingement point and in the rolls $(\sim 1778 \mathrm{~K})$. In the copper mould, the maximum temperature $(\sim 702 \mathrm{~K})$ was located at approximately $45-55 \mathrm{~mm}$ below the meniscus level. The back of the
Table 2. Simulated casting conditions.

\begin{tabular}{|c|c|}
\hline \multicolumn{2}{|c|}{ Mould oscillation settings } \\
\hline Frequency (c.p.m.) & 100 \\
\hline Stroke $(\mathrm{mm})$ & 10 \\
\hline \multicolumn{2}{|c|}{ Casting conditions } \\
\hline Casting speed (m/min) & $0.6,0.9,1.2,1.5,1.8$ \\
\hline Superheat (K) & $20,40,60$ \\
\hline $\begin{array}{l}\text { Water flow rate in cooling } \\
\text { channels }(\mathrm{m} / \mathrm{s})\end{array}$ & $10,20,30$ \\
\hline $\begin{array}{l}\text { Interfacial resistance } r_{\text {int }} \\
\left(m^{2}-K / W\right)\end{array}$ & $5 \times 10^{-5}, 2 \times 10^{-4}, 8 \times 10^{-4}$ \\
\hline
\end{tabular}

a)

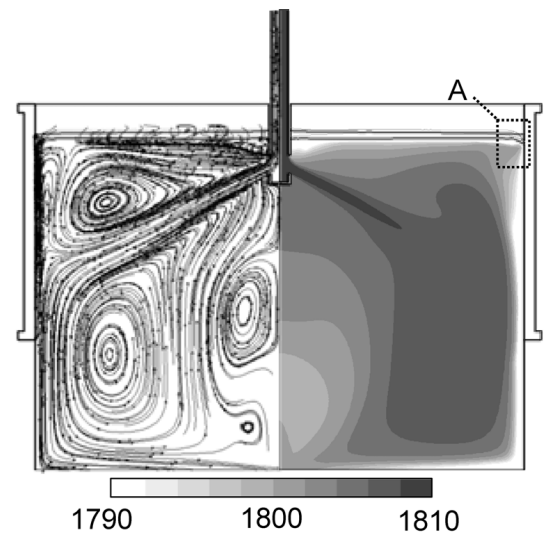

b)

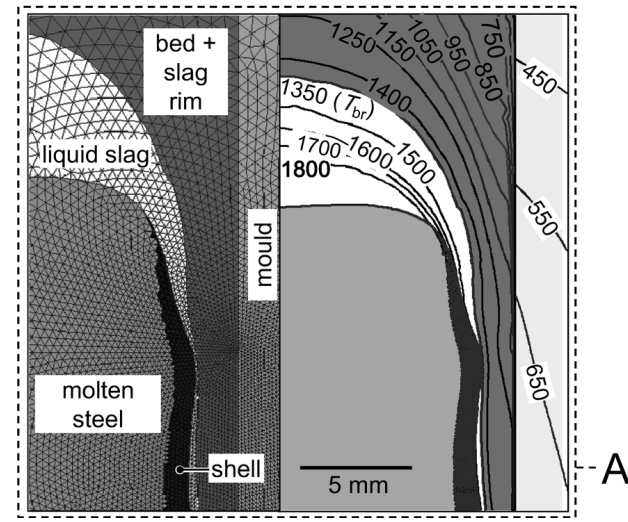

Fig. 2. Model predictions for $v_{c}=0.9 \mathrm{~m} / \mathrm{min}$ : (a-lhs) flow; (a-rhs) temperature field; (b-lhs) computational mesh; and (brhs) molten steel (medium-grey), shell (black), liquid slag layer (white), solid slag (dark grey).

mould remains close to $393 \mathrm{~K}$ along most of the water jacket surface. The calculated liquid and solid slag layers (light and dark grey) are shown in Fig. 2(b), together with the liquid steel and solid shell (white and black). Note that the location where solidification initiates (near the meniscus) as well as the shell shape, are predicted by the model rather than being fixed a priori. The left hand side of Fig. 2(b) shows the very high degree of mesh refinement required to predict these phenomena (i.e. minimum cell size $<100 \mu \mathrm{m})$.

Infiltration into the shell-mould gap occurs as a thin film ( $d_{\text {liquid }}$ of $\sim 150$ to $600 \mu \mathrm{m}$ depending on $v_{c}$ ) of liquid slag travelling with the steel shell as it is pulled downwards. The model also predicts a solid slag layer $\left(d_{\text {solid }}\right)$ of approximately $1.5 \mathrm{~mm}$ in thickness between the liquid channel and mould side for the case shown $\left(v_{c}\right.$ of $\left.0.9 \mathrm{~m} / \mathrm{min}\right)$. The inter- 
facial tension between metal and slag plays an important role in this infiltration and determines the characteristic curvature at the meniscus corner, which was effectively predicted in the simulations (Fig. 2(b)). The meniscus profile exhibits a more complex structure for the slag-metal interface and the slag rim than those predicted by the Bikerman equation. This suggests that infiltration in the shell-mould gap is strongly affected by other phenomena occurring far from the meniscus corner (such as jet oscillations and level fluctuations as proposed by Lee et al. ${ }^{25}$ ) These transient events are mainly related to the metal flow delivered by the SEN and involve different time and length scales to those of mould oscillation. These phenomena were defined recently by Badri et $a l^{26)}$ as low frequency phenomena, whereas the events related to mould oscillation were denoted as high frequency phenomena.

\subsection{High and Low Frequency Phenomena}

Figure 2 shows a snapshot of the transient flows, slag layers and temperature contours once a "steady state" has been reached. Although termed "steady state", this does not imply that changes in metal flow and temperature do not occur. Instead, we simply mean that a regular shell formation and a uniform slag film have developed throughout the mould length. In fact, there are continuous fluctuations in both the flow and thermal fields even when, what is termed, "steady state" casting has been achieved. Furthermore, these fluctuations have a cyclic nature that has been observed in experimental studies. ${ }^{26,27)}$ These low frequency phenomena are due to the turbulent nature of the flow leaving the nozzle, which produces variations in the intensity and angle of the discharging jets, as well as wave-like oscillations of the slag-metal interface. ${ }^{19)}$ The effect of these low frequency phenomena on slag infiltration and heat extraction are successfully traced with the current model, which predicts (as shown in Fig. 3) the solid slag film thickness $\left(d_{\text {solid }}\right)$ and heat flux density $(q)$ as a function of time for a point $45 \mathrm{~mm}$ below the meniscus level.

The solid slag layer and heat flux were found to vary at three different frequencies (Fig. 1), the highest being locked into the mould oscillation frequency $(0.6 \mathrm{~s})$, a typical low frequency (see solid-line oscillations of approximately 20-25 s), and a very low frequency phenomena (not shown in the figure) on a time scale of minutes. Although the analysis of this very low frequency behaviour is being addressed by the authors in ongoing research, it requires extensive calculations over long periods of time (significant computational effort); and therefore, is beyond the scope of this text. Nevertheless, both the low and the very low frequency behaviour affect the measurement of any variable traced during an oscillation cycle by increasing or decreasing its mean value.

High frequency phenomena are produced by the continuous vertical oscillation of the mould. This oscillation is defined by the mould velocity $\left(v_{m}\right)$ and displacement $\left(m_{\text {disp }}\right)$, as shown in Fig. 4. It is customary to discuss the effects of oscillation in terms of negative and positive strip times, $\left(t_{n}\right)$ and $\left(t_{p}\right)$, respectively. Negative strip occurs when the downward velocity of the mould is faster than the casting speed in the withdrawal direction $\left(v_{m}>v_{c}\right.$, Fig. 4(b)-middle). However, in this particular case, $v_{c}$ was defined as nega-

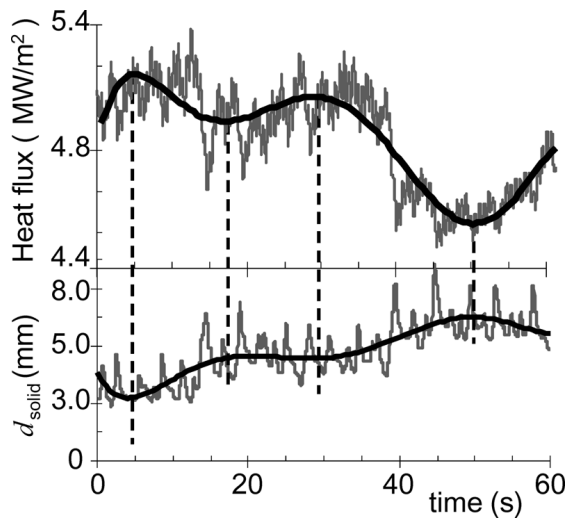

Fig. 3. Heat flux and solid slag film thickness $\left(d_{\text {solid }}\right)$ as a function of time (100 cycles) for $=0.6 \mathrm{~m} / \mathrm{min}$.

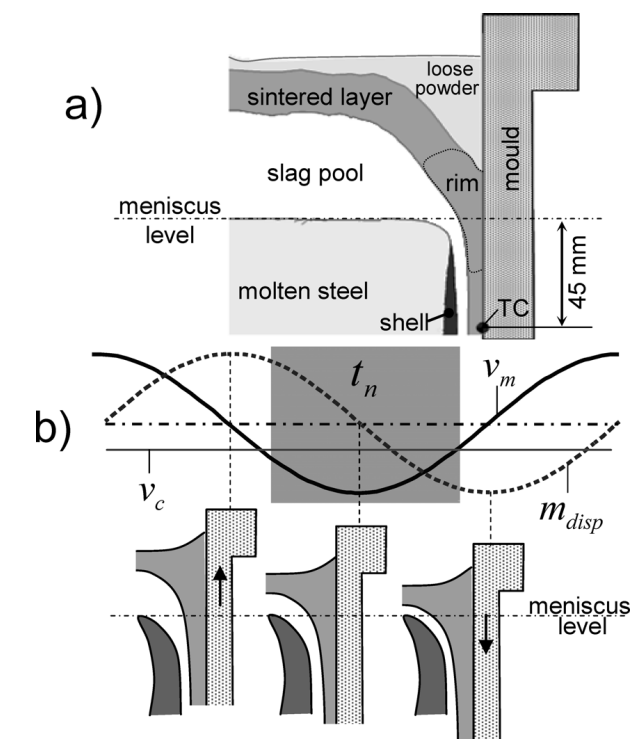

Fig. 4. (a) Predicted liquid and sintered slag layer profiles and shell in the meniscus region, with schematically added loose power layer and mould. (b) Schematic of mould oscillation effects on shell-slag interaction.

tive in the downwards direction, thus, $t_{n}$ occurs when $\left|-v_{m}\right|>\left|-v_{c}\right|$. The positive strip time refers to the rest of the oscillation cycle. These oscillation characteristics strongly affect the slag infiltration and solidification, as explained below.

\subsection{Slag Infiltration}

To understand the infiltration mechanism, a detailed description of the inflow of molten slag entering the shellmould gap is required, as shown in Fig. 5. This liquid slag forms a channel that runs from the slag pool to a constriction (dotted circle in Fig. 5(a)), where the slag film initiates. The width of the liquid slag film was calculated by determining the distance between the surface of the shell and slag break temperature $\left(T_{b r}, 1350 \mathrm{~K}\right)$ isotherm. The first observation made from Fig. 5 is the irregular shape of the liquid slag channel, especially at the rim surface. This bears a closer resemblance with actual rim samples obtained in plant trials ${ }^{28)}$ than with the profiles calculated through the Bikerman equation. ${ }^{29)}$ The figure also illustrates how the metal-slag interface deforms to balance the forces generated by interfacial tension with the pressure exerted by the 


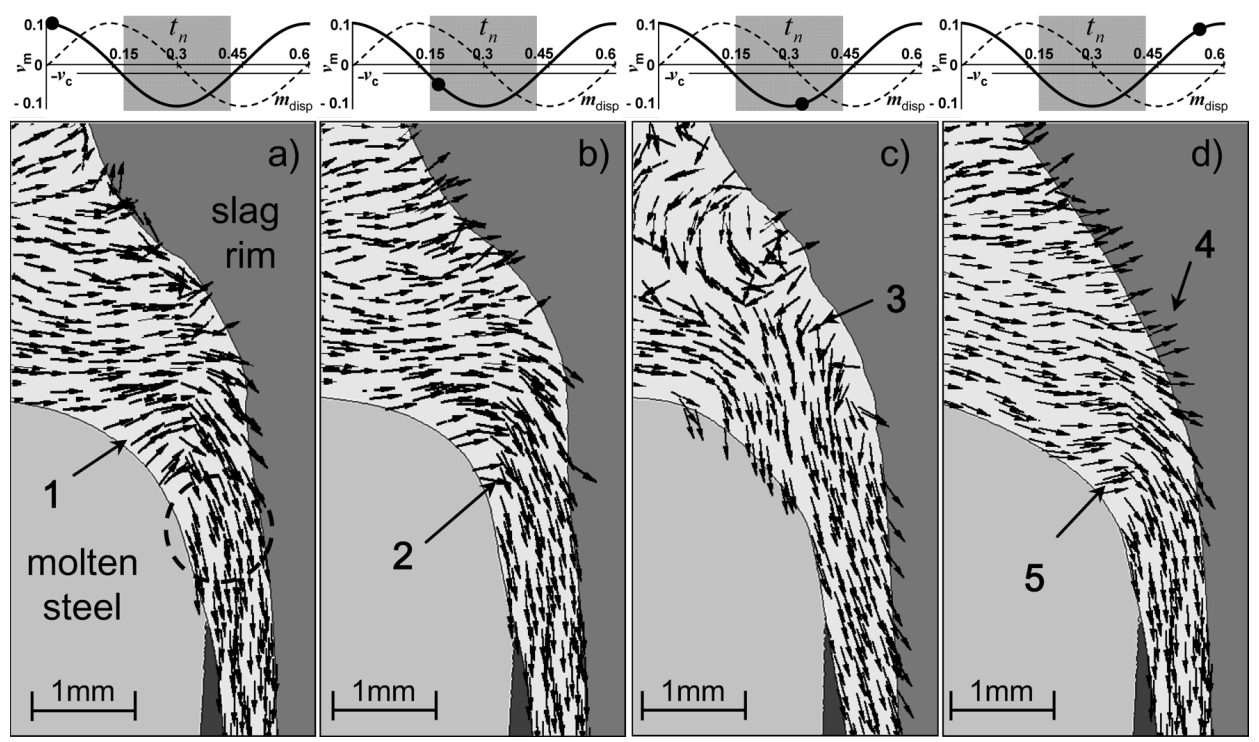

Fig. 5. Predicted slag flow in the meniscus for $v_{c}=0.6 \mathrm{~m} / \mathrm{min}$ at four points (solid dot on mould velocity curve) during an oscillation cycle: (a) halfway through positive strip; (b) beginning of negative strip; (c) approximately half way through negative strip; and (d) returning to halfway through positive strip.
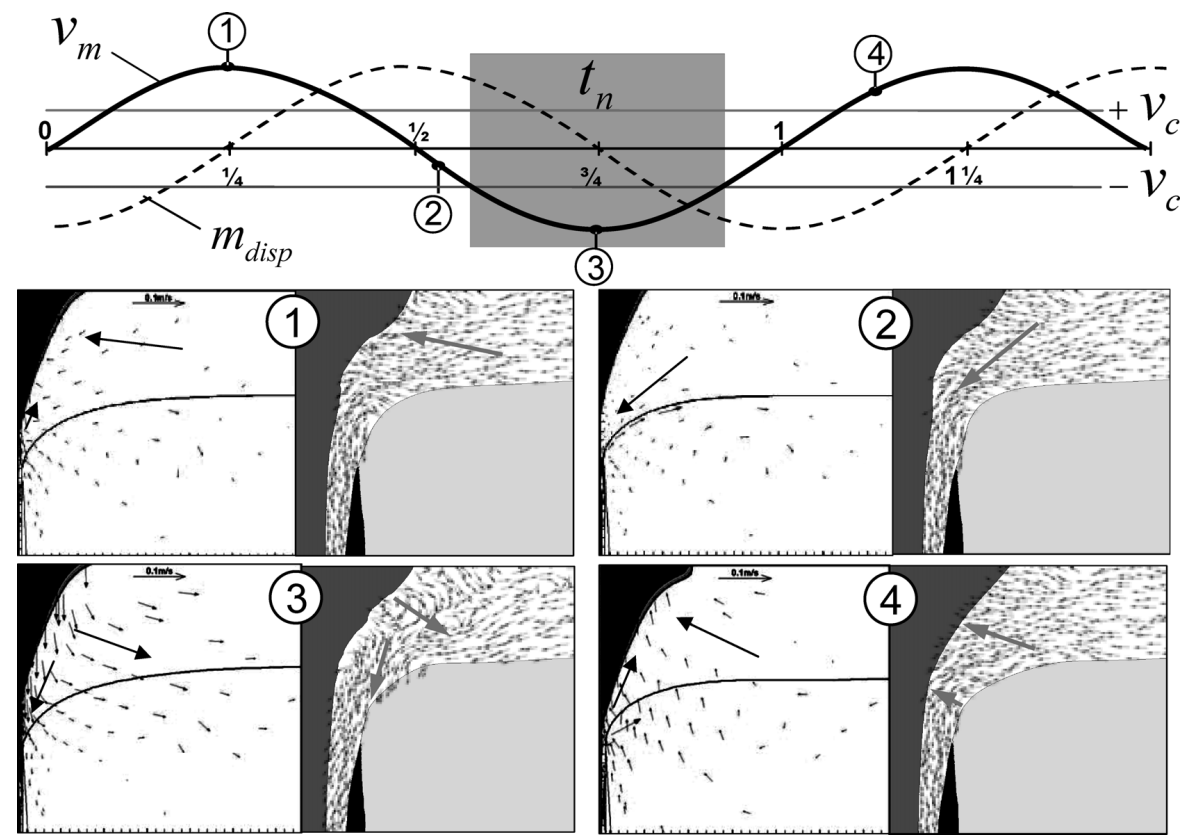

Fig. 6. Comparison of predicted slag flows in the meniscus-region of slag pool from this study (rhs) with those predicted by Ojeda et $a .^{29}{ }^{29}(\mathrm{lhs})$ at different periods of cycle. (Note $1 \frac{1}{2}$ cycles are shown. $v_{c}=0.9 \mathrm{~m} / \mathrm{min}$ for present simulations, $v_{c}=1.5 \mathrm{~m} / \mathrm{min}$ in Ojeda et al.'s simulations.)

rim during the oscillation cycle. The shape and width of the channel are determined by the interaction of the various forces acting at the interface, namely, the ferrostatic pressure and the pressure of slag influx.

Further analysis of the flow patterns of liquid slag in Fig. 5 shows that slag infiltration is closely related to the mould velocity and mould displacement during the cycle. For instance, the cycle starts with counter-flows at the entry of the gap (1 in Fig. 5(a)-mould travelling upwards). Then, the counter-flow both decreases and moves downwards, disappearing later in the cycle and allowing partial infiltration (2 in Fig. 5(b)). Infiltration occurs partly during the negative strip time, $t_{n}$, due to a pumping effect produced by the downwards movement of the mould and slag rim (3 in Fig. 5(c)). This infiltration continues through part of the positive strip time, $t_{p}$, until the flow is redirected upwards again by the mould displacement (4 in Fig. 5(d)). Finally, counterflows appear at the end of the cycle when the mould is again at its highest position (5 in Fig. 5(d)).

In order to corroborate these results, the flow patterns of liquid slag in the meniscus are compared to those simulated by Ojeda et al. ${ }^{29)}$ in Fig. 6. Comparison of flow directions in the slag pool at various points throughout the oscillation cycle show very good agreement. Note that Ojeda's model only simulates the liquid slag and does not provide any information about the thermal evolution in the meniscus, which is actively changing the thicknesses of the liquid and solid slag layers. Furthermore, the results obtained in this 
study show that the slag-metal interface deforms to accommodate the local flows of metal/slag in the meniscus and the effect of the rim. Previous models have not taken this into account. In this case, flow patterns provide the first piece of information about the infiltration mechanism, whereas the liquid slag film thickness provides a measure of the lubrication (powder consumption) supplied. On the other hand, the pumping effect produced by the descending rim (as proposed initially by Emi et al. ${ }^{30}$ ) and illustrated by Ojeda et $\left.a{ }^{29}{ }^{29}\right)$ has been confirmed in the simulations.

There has been a long debate on the factors affecting slag infiltration with some investigators proposing that infiltration occurs in the negative strip time and others claiming that slag infiltration occurs in the positive strip time. In order to compare the current results with those reported previously, two reference points were defined during the oscillation cycle, namely, $v_{m}=+v_{c}$ and $v_{m}=-v_{c}$. The latter corresponds to the beginning of $t_{n}\left(-v_{c}\right.$ is the velocity in the casting direction). Figure 7 compares the transients for the thicknesses of solid and liquid slag layers during one cycle with those for oil thickness recorded in a cold model experiment by Kajitani et al. ${ }^{31)}$ The results show that the evolution of the solid slag film $\left(d_{\text {solid }}\right)$ is very similar to that reported by Kajitani et al. for the oil thickness. Both reach a maximum thickness when $v_{m}=+v_{c}$ (just before the start of $t_{n}$ ), and decrease steadily through $t_{n}$, falling to a minimum when $v_{m}=0$. At this point, $d_{\text {solid }}$ starts to grow steadily during $t_{p}$ until it reaches a maximum when $v_{m}=+v_{c}$ (end of upwards displacement). These results confirm that $d_{\text {solid }}$ decreases mainly during the negative strip time (mould travelling downwards) and increases throughout positive strip periods (mould travelling upwards). In contrast, the behaviour of the liquid layer thickness during the cycle is a mirror image of the solid layer behaviour. This implies that the slag film is the result of melting/freezing cycles, where the liquid layer grows at expense of the solid as the mould is travelling downwards to hotter regions. Conversely, the liq-

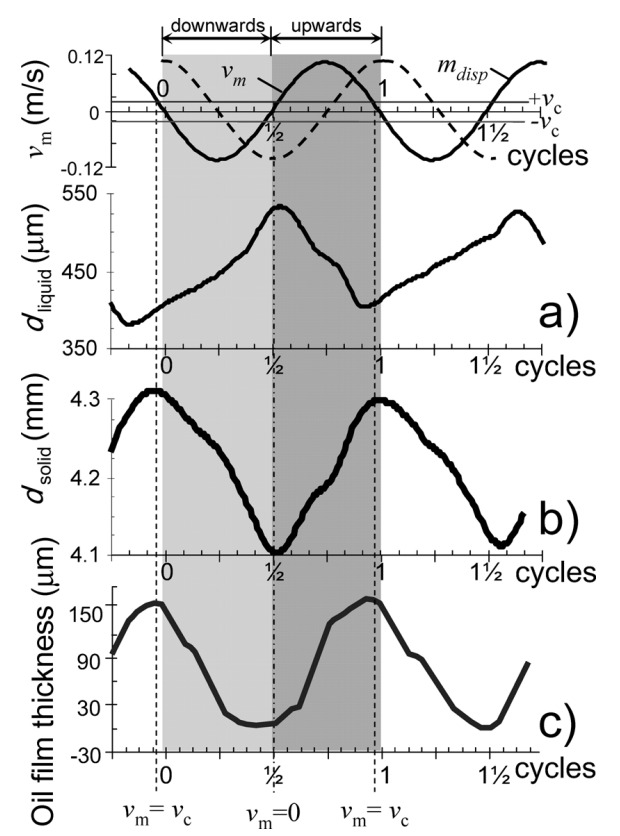

Fig. 7. Comparison (a) liquid and (b) solid slag layer thicknesses predictions through an oscillation cycle with (c) oil film thickness in cold model reported by Kajitani et al. ${ }^{31)}$ uid slag tends to freeze as the mould moves upwards, away from the heat source. This mechanism is also evident in the formation of the rim due to the solidification of slag in the mould corner just above the meniscus.

Kajitani's experiment is able to capture the effects of thickening and thinning of the oil film in the gap during the oscillation cycle. However, the lack of a solid layer in the experiment suggests that the measured effects apply only to geometrical changes in the gap derived from the artificial taper assigned to the mould side. Nevertheless, the overall effect is equivalent to the remelting of the solid slag layer in the current simulations as the mould moves downwards (effectively increasing the thickness of the liquid). Although this comparison provides a good validation of the widening/thinning cycles on the slag film, it is also important to examine the heat transfer evolution of the solid and liquid layers, which requires an analysis of the heat flux and shell growth.

\subsection{Heat Flux Evolution}

The predicted heat fluxes at the narrow face centreline for a position $45 \mathrm{~mm}$ below the meniscus and $v_{c}=1.2 \mathrm{~m} / \mathrm{min}$ were compared in Fig. 8 with those obtained by Badri et al. in a laboratory-based mould simulator. ${ }^{26,27)}$ In this case, heat flux transients exhibit a sudden increase at the start of $t_{n}$, which is in excellent agreement with Badri's measurements. Furthermore, the periodicity of the heat flux with oscillation is also in good agreement with the experiments. It is also noticeable that the heat flux in the simulations increased consistently with a local plateau at $1 / 4$ cycle followed by a further increase up to a local maximum at approximately $t=1 / 2$ cycle. The heat flux drops dramatically at the end of the positive strip time to complete the oscillation cycle.

The transients for slag film evolution and heat flux presented in Figs. 7 and 8 are representative of those obtained for all casting speeds and cover the same period of time to aid the comparison of heat flux vs. slag film thickness during oscillation. Assessment of these figures shows a strong inverse correlation between solid slag film thickness and

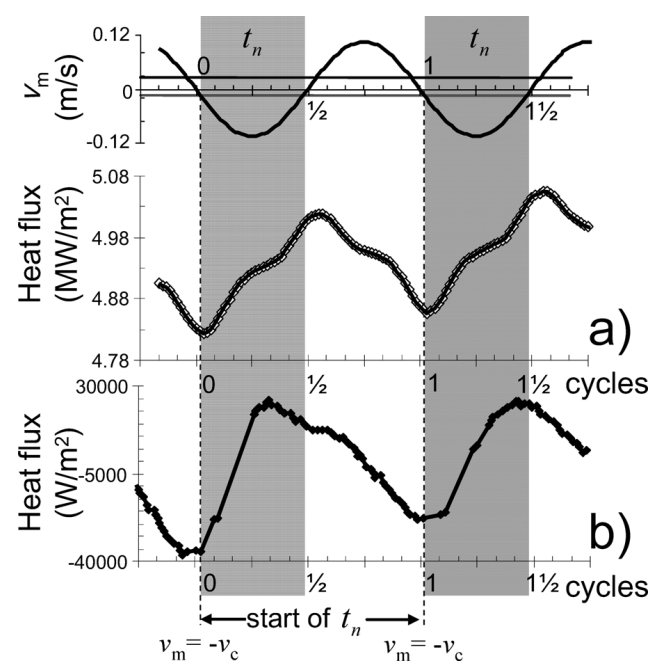

Fig. 8. Comparison of the variation in heat flux during an oscillation cycle (a) predicted by the current model $\left(v_{c}=1.2 \mathrm{~m} / \mathrm{min}\right)$ and (b) measured by Badri et al. ${ }^{26,27)}$ in a mould simulator. 
heat flux evolution, where increases in heat flux are associated with concomitant decreases in solid slag thickness. This inverse dependency is consistent with Eq. (4) since an increase in thermal resistance is expected from a thicker solid slag film. Additionally, the points where $v_{m}$ intersects $\pm v_{c}$ define local maxima and minima throughout the cycle, confirming the influence of mould oscillation on infiltration and heat delivery to the mould.

The excellent correlation of the predicted results to the findings of two prior experimental studies focused on completely different aspects of the casting process and with very particular physical nature supports the validity of the modelling approach employed in this investigation. Moreover, comparisons with a numerical model focused entirely on the slag flow in the meniscus confirms the self-consistency of the results obtained, where calculation of small scale events such as infiltration match with macro-scale events such as heat flow across very different time-scales. This self-consistency allowed the deduction of physical mechanisms for infiltration and solidification, as explained in the following sections.

\subsection{Slag Infiltration and Initial Shell Solidification Mechanisms}

The mechanism of slag infiltration is shown in Fig. 9, where the flow of slag into the solid slag/shell gap and the changes in solid and liquid slag film thicknesses (exaggerated to demonstrate the mechanism) are correlated with measured transients for various parameters during the oscillation cycle $\left(v_{c}=0.9 \mathrm{~m} / \mathrm{min}\right)$. (Note, the values of pressure, velocity and temperature are the average value across the liquid slag layer at $45 \mathrm{~mm}$ below the meniscus.) Starting at half negative strip time, the slag rim produces a pumping effect as the mould travels downwards and liquid slag is pushed to fill-in the gap. The pressure exerted by the slag rim is transmitted through the fluid producing periodic perturbations in the slag-metal interface, which imprint a hollow shape on the interface for every cycle as the shell moves downwards. The new shape of the channel produces accumulation of liquid slag into bursts that move down along the interface in a similar way to a slug flow. Right at the end of $t_{n}$, the mould reaches its lowest position bringing the slag rim closer to the shell (the source of heat in this case). This proximity causes remelting of the solid slag, thereby increasing the liquid film thickness to a maximum just after the mould begins to travel upwards. Although infiltration increases steadily during this negative strip, the peak in infiltration (i.e. consumption) occurs in the first half of the positive strip time, when the liquid slag film is at its maximum (mould starting to travel upwards). This fact explains why slag consumption has been found to increase with increasing positive strip time in industrial practice. ${ }^{32)}$ The results also indicate that positive slag infiltration occurs throughout the oscillation cycle but decreases in the second half of the positive strip due to the decrease in liquid film thickness as the solid film recovers. No cases of negative consumption rates were identified in the cycle for the casting parameters studied here.

Average temperatures across the liquid film are consistent with these findings since a peak in temperature can be found when the liquid slag film is at its maximum thickness, while the minimum temperature occurs when the solid layer is at a maximum. These cycles of thinning and thickening of the slag layers in the film respond to the proximity of the mould (the solid film re-melts if it is closer to the shell or freezes when the mould is far from the heat source). Higher temperatures are also expected to enhance the fluidity (i.e. reciprocal viscosity) of the slag entering the gap and hence, increase consumption. Additionally, the pressure and velocity that characterize the liquid film agree

a)
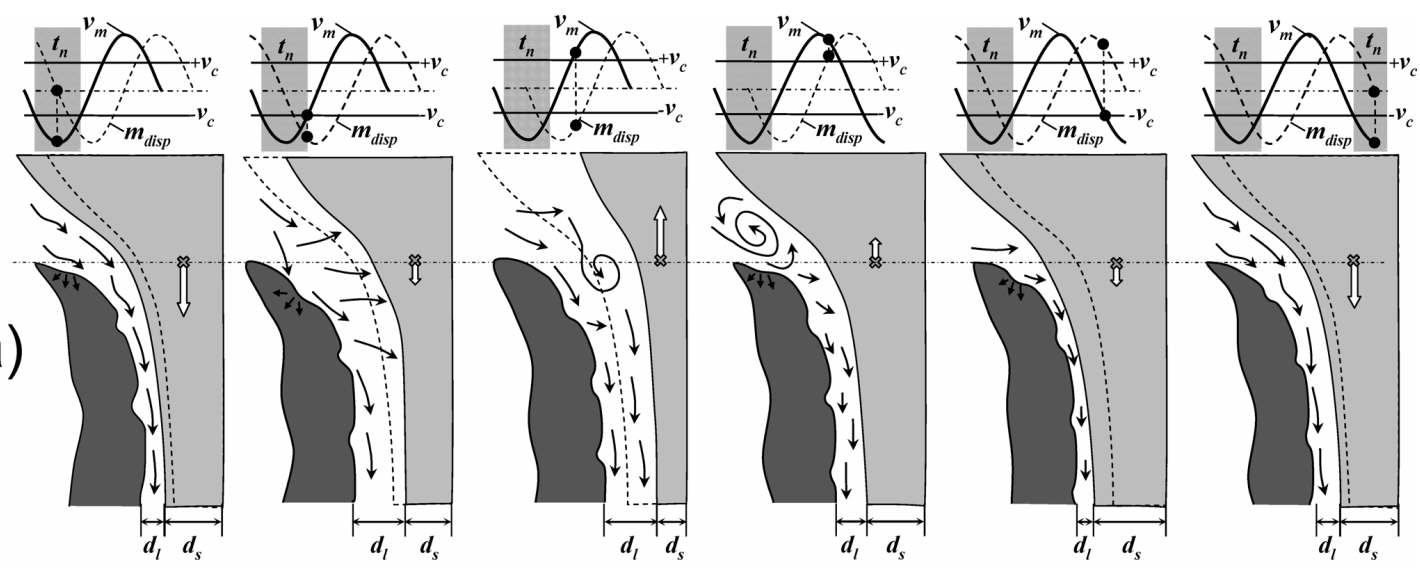

b)

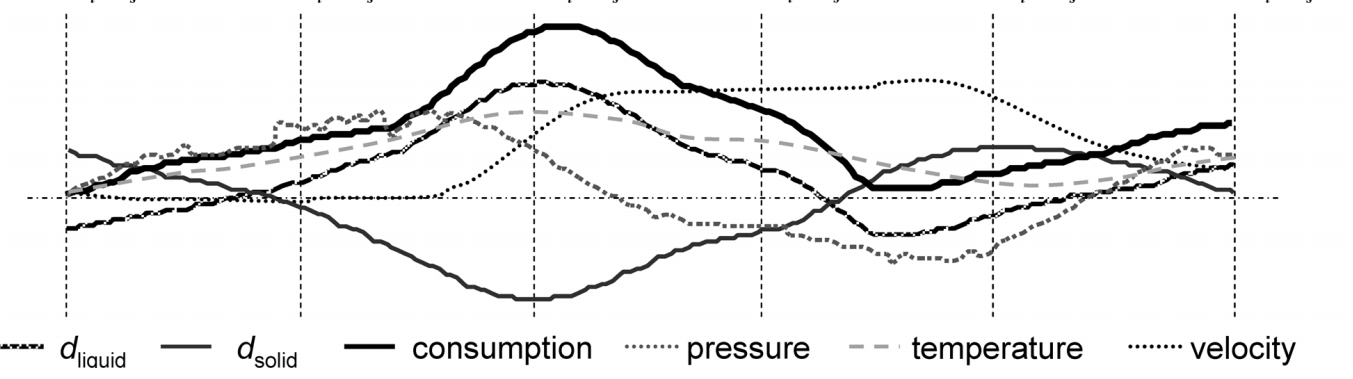

Fig. 9. (a) Schematic of the slag infiltration mechanism throughout an oscillation cycle and (b) corresponding predicted typical evolution of $d_{\text {solid }}, d_{\text {liquid, }}$, powder consumption, temperature, pressure and velocity $\left(v_{c}=0.9 \mathrm{~m} / \mathrm{min}\right)$. 
with physical principles. For instance, velocity is a mirror image of the pressure in the liquid film complying with the Bernoulli principle. Furthermore, the pressure increases as the liquid film thickens reducing the velocity of the molten slag; otherwise, the thinning of the film reduces the pressure and increases the velocity. Consequently, the relationship between, $d_{\text {liquid }}$, pressure and velocity is maintained to ensure that the continuity law is preserved.

Initial solidification of the shell occurs along the computed, tortuous, slag-metal interface (shown in Figs. 5, 6 and 9) creating a shell of uneven thickness, which is pulled downwards at the casting speed. In order to explore the mechanism of initial solidification, the transients for shell thickness and heat flux have been plotted in Fig. 10 for an oscillation cycle $\left(v_{c}=0.9 \mathrm{~m} / \mathrm{min}\right)$. Variations in the shell surface have been exaggerated by several orders of magnitude to highlight differences in the surface roughness. Schematics of solid and liquid slag film thicknesses are also presented in Fig. 10 to illustrate how changes in the mould temperature $\left(T_{\text {mould }}\right)$, shell temperature $\left(T_{\text {shell }}\right)$ and break temperature $\left(T_{b r}\right)$ affect the solid and liquid layers in the slag film, and hence, the heat flux evolution during the cycle. Shell thicknesses correlate well with local minima and maxima in heat flux and film thicknesses, which occur at key points in the cycle. For instance, at the beginning of negative strip time $\left(v_{c}=-v_{m}\right)$, the mould is close to its highest point and heat flux is at a minimum; consequently, the rate of shell solidification is low. Furthermore, as $t_{n}$ proceeds the descending rim pushes the steel-slag interface giving rise to periodic depressions in the shell surface, which the authors consider as the origin of oscillation marks (OM's). However, the current model does not simulate the deformation or shrinkage of the shell, which are thought to play an important role in the final shape of an OM. ${ }^{1)}$ Nevertheless, the mechanism proposed here offers an explanation of the initiation of OM's due to the cyclic nature of solidification within the mould. Support for this hypothesis can be derived from the pitch of the periodic depressions in the surface predicted by the present model. Mean values for $v_{c}=0.6,0.9,1.2$ and $1.5 \mathrm{~m} / \mathrm{min}$ are $6.1,9.1$, 11.8 and $15.0 \mathrm{~mm}$, respectively. This is in excellent agreement with the values for the theoretical pitch $(6,9,12$ and $15 \mathrm{~mm}$, respectively) of oscillation marks $\left(D_{\text {om }}\right)$ defined by Eq. (5). ${ }^{33)}$ Furthermore, this hypothesis is consistent with

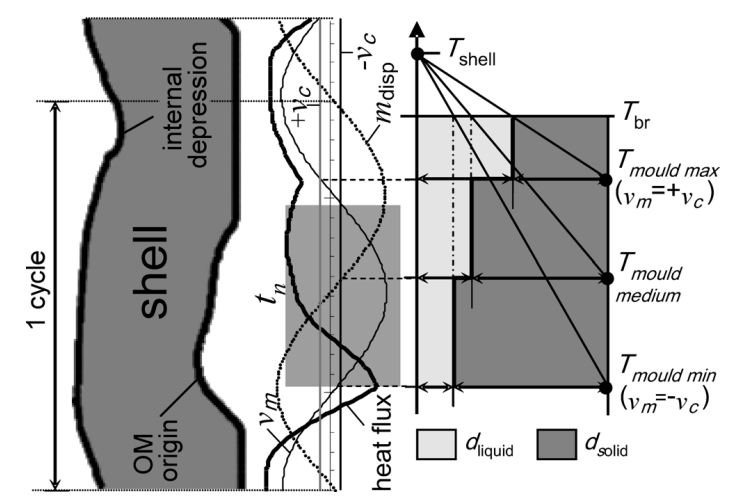

Fig. 10. Predicted shell surface profile (lhs) and heat flux evolution (middle) throughout a cycle and corresponding liquid $\left(d_{\text {liquid }}\right)$ and solid $\left(d_{\text {solid }}\right)$ slag layer thickness $\left(v_{c}=0.9 \mathrm{~m} / \mathrm{min}\right)$. plant measurements since it is well known that the depth of oscillation marks can be reduced by decreasing the negative strip time, as derived by Szekeres ${ }^{33,34)}$.

$$
D_{o m}=\frac{v_{c}}{f}
$$

All of the trends discussed in this section (Figs. 9 and 10) were observed over a wide range of casting speeds from 0.6 to $1.8 \mathrm{~m} / \mathrm{min}$, although the magnitude of the variations varied. It should be noted that the shell grows by increasing the heat flux and decreasing $d_{\text {solid }}$. In contrast powder consumption is a function of $d_{\text {liquid }}$. Thus, it can be concluded that the liquid slag film controls lubrication, while the solid slag film controls solidification. Therefore, the onset of defects such as oscillation marks is the result of the transient interaction between lubrication and solidification produced by the mould oscillation.

\subsection{Comparison to Industrial Measurements and Model Limitations}

Values for shell thickness and powder consumption at various casting speeds ( 0.6 to $1.8 \mathrm{~m} / \mathrm{min})$ are compared with the recent plant measurements (due to Hanao et al. ${ }^{35)}$ ) in Fig. 11 to further validate the model predictions. These measurements refer to a position $45 \mathrm{~mm}$ below the meniscus; and consequently, this position was used as reference point for the present calculations. Figure 11 shows that predicted shell thicknesses are in good agreement with Hanao's equation for different casting speeds. In this case, the model consistently replicates the reduction in initial shell thickness due to increases in casting speed, showing a better fitting at intermediate and high casting speeds ( 0.9 to $1.8 \mathrm{~m} / \mathrm{min}$ ) than on the low $v_{c}$ side (scattering at $v_{c}=0.6 \mathrm{~m} / \mathrm{min}$ ). This discrepancy at very low casting speeds is due to the large variations in solid slag film thickness $(<4 \mathrm{~mm})$ and hence shell thickness.

In Fig. 12, powder consumption $\left(Q_{s}\right)$ is compared with empirical equations based on plant measurements by Wolf and Ogibayashi ${ }^{36)}$ and a numerical model due to Shin et $a{ }^{32)}$ Current model predictions show reasonable agreement at intermediate and high casting speeds. Powder consumption was calculated by dividing the measured consumption for the liquid film layer at $45 \mathrm{~mm}$ (shown in the calcula-

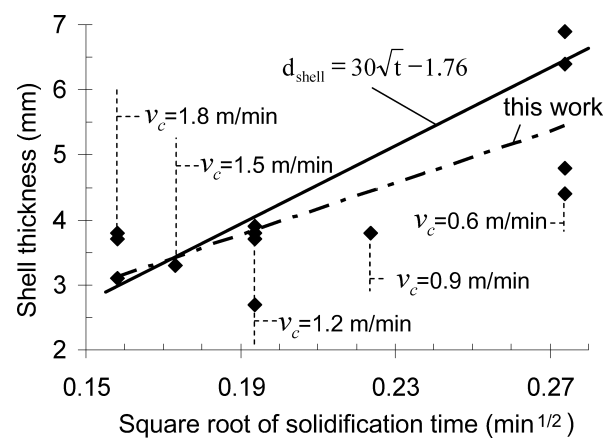

Fig. 11. Comparison of predicted shell thickness to those measured by Hanao et $a l^{39)}$ as a function of solidification time $(t)$ for different casting speeds. (Measurementssolid line; diamonds this study's predictions; and best fit to predictions-dotted line.) 


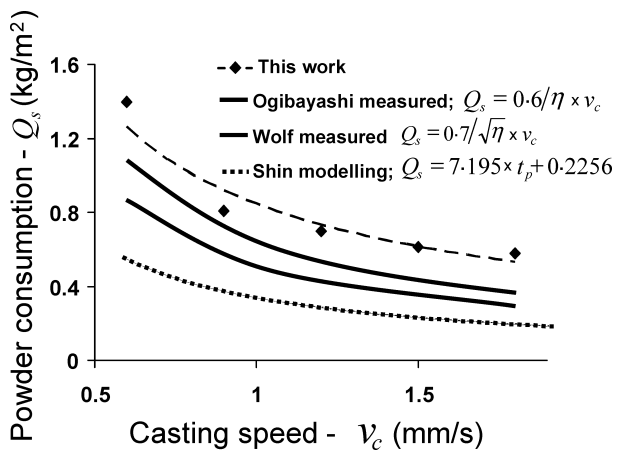

Fig. 12. Comparison of calculated powder consumption $\left(Q_{s}\right)$ as a function of casting speed to prior measurements by Ogibayashi and Wolf ${ }^{36)}$ and a model by Shin et al. ${ }^{32)}$

tions) between the perimeter of the slab $(1.88 \times 0.27 \mathrm{~m})$ multiplied by the casting speed.

$$
Q_{s}=\frac{Q_{\text {liquid-film }}}{\text { Perimeter }_{\text {slab }} \times v_{c}}=\frac{\frac{\mathrm{kg}}{\mathrm{s}}}{\mathrm{m} \times \frac{\mathrm{m}}{\mathrm{s}}}=\frac{\mathrm{kg}}{\mathrm{m}^{2}}
$$

It was also found that the liquid slag thickness increased slightly when descending the mould, which is in agreement with the predictions of Okazawa et al. ${ }^{37)}$ The most remarkable result is the replication of the effect of casting speed on consumption, since it is well known from plant measurements that increases in $v_{c}$ lead to decreases in consumption. However, with exception of the numerical models based in plant data fitting by Meng ${ }^{16)}$ and Shin, ${ }^{32)}$ or the physical model by Kajitani, ${ }^{31)}$ this relationship has not been reproduced even qualitatively by previous models.

Predicted consumption figures are slightly higher $(\sim 6 \%)$ than those from plant data and other models at intermediate casting speeds, but depart more considerably from measurements at high casting speeds $(25 \%)$. Possible reasons for this behaviour are:

(i) Increases in positive strip time with increasing casting speed would lead to increased $Q_{s}$ (since frequency and stroke were maintained constant in the simulations) on the basis of results shown in Fig. 8.

(ii) Increasing $Q_{s}$ is needed when casting wider slabs. It is estimated that $Q_{s}$ for a width of $1.88 \mathrm{~m}$ (used in present study) would be $10 \%$ higher than that for average slabwidths $(\sim 1.4 \mathrm{~m}) .^{15)}$

(iii) Values due to Shin et $a l .{ }^{32)}$ would be expected to be low since they refer to a slag viscosity of $3.2 \mathrm{dPs}$ (cf. $1.115 \mathrm{dPs}$ in present study). Wolf and Ogibayashi equations indicate that $Q_{s}$ for Shin conditions should be increased by 167 and $278 \%$, respectively, to compare with $Q_{s}$ values in the present study.

(iv) The current model is two-dimensional. Under full three dimensional conditions, the slag film is expected to be thicker towards the mould corners due to the shrinkage of the slab, but would also suffer combined heat extraction from the narrow and wide faces. In consequence, despite having a thicker film in the corners; it would be also cooler and the amount of liquid slag infiltration (i.e. consumption) should decrease.

\section{Conclusions}

A numerical model which couples the metal flow, heat transfer and solidification with slag infiltration in the continuous casting mould has been successfully developed. The model is able to characterize the slag infiltration phenomena and initial shell solidification in the meniscus by coupling physical phenomena across a wide range of time and length scales to produce an integrated model of the continuous casting process. The following conclusions were drawn from the application of this model:

(1) Metal and slag flows in the mould are in a constant state of fluctuation. Thus, the evolution of any variable $\left(d_{\text {solid }}, d_{\text {liquid, }}\right.$, heat flux, etc. $)$ can be divided into a high frequency component (instantaneous component) related to mould oscillation and a low frequency component (mean component) related to events occurring far from the meniscus at different length and time scales.

(2) Changes in the slag flow direction and in consequence, infiltration, always occur on the same period during the oscillation cycle, independently of changes of $v_{c}$.

(3) Local maxima and minima of infiltration and heat flux occur at key points in the cycle $\left(t_{n}, t_{p}, m_{\text {disp }}=0\right)$. The maximum values for $d_{\text {solid }}$ and $d_{\text {liquid }}$ occur close to the beginning of $t_{n}\left(v_{m}=+v_{c}\right)$ and start of $t_{p}\left(v_{m}=0\right)$, respectively.

(4) Thickness of solid and liquid slag layers $\left(d_{\text {solid }}\right.$ and $\left.d_{\text {liquid }}\right)$ maintain an inverse relationship throughout the cycle. $d_{\text {solid }}$ re-melts when the mould travels downwards, increasing $d_{\text {liquid. }}$. Conversely, $d_{\text {liquid }}$ decreases when the mould travels upwards and $d_{\text {solid }}$ re-solidifies.

(5) Consumption is directly related to the thickness of the liquid slag layer $\left(d_{\text {liquid }}\right)$ and it occurs partly during $t_{n}$ but reaches a maximum in the first half of $t_{p}$ to finally decrease in late $t_{p}$. Negative consumption was not detected at any part of the oscillation cycle in this study.

(6) Temperature, pressure and velocity within the liquid film are self-consistent with physical principles such as the Bernoulli equation and the Conservation law.

(7) There is an inverse relationship between heat flux $(q)$ and the thickness of the solid slag layer $\left(d_{\text {solid }}\right)$ during the cycle with the heat flux increasing throughout $t_{n}$ and decreasing in $t_{p}$.

(8) Periodic depressions are imprinted on the shell surface as the mould moves downwards in $t_{n}$. A decrease in the shell solidification rates due to heat flux reductions during $t_{n}$, contribute to the formation of such depressions These depressions are considered to be the origin of oscillation marks.

(9) Predicted shell thicknesses, heat fluxes and powder consumption are in good agreement with measurements obtained in plant trials and other models.

Replication of the complex phenomena measured in experiments and other numerical models validates the modelling approach used in this study. Results provide new insights into the mechanisms of infiltration and initial solidification, which are essential for the prediction and correction of typical defects such as oscillation marks and transverse cracks.

\section{Acknowledgements}

PRL would like to thank CONACYT and SEP (Mexico) 
for financial assistance to attend his $\mathrm{PhD}$ studies at Imperial College London. The authors thank the EPSRC (GR/T26344) for facilities and CORUS for financial support.

\section{Nomenclature

\begin{aligned}$\alpha: &$ Phase fraction \\ $d: &$ Thickness \\ $\rho: &$ Density \\ $\vec{u}, \vec{v}: &$ Velocity vectors \\ $m: &$ Mass flux \\ $t: &$ Time \\ $p: &$ Pressure \\ $\mu: &$ Viscosity \\ $\beta: &$ Body forces \\ $T: &$ Temperature \\ $g: &$ Gravity force \\ $\sigma: &$ Surface tension \\ $\kappa: &$ Curvature \\ $r_{\text {int }}: &$ Interfacial resistance \\ $q_{\mathrm{hor}}: &$ Horizontal heat flux \\ $d: &$ Slag film thickness \\ $Q_{s}: &$ Powder consumption \\ $t_{n}: &$ Negative strip time \\ $t_{p}: &$ Positive strip time \\ $v_{c}: &$ Casting speed \\ $v_{m}: &$ Mould velocity \\ $m_{\mathrm{disp}}: &$ Mould displacement \\ $f: &$ Mould frequency \\ $D_{O M}: &$ Oscillation mark pitch \\ \hline${ } & \end{aligned}$

Subscripts

$p, q: \quad$ n-phase (steel, slag or air)

mix : Phase mixture in VOF model

\section{REFERENCES}

1) J. Sengupta and B. G. Thomas: JOM-e, 58, (2006)

2) J. Elfsberg: PhD Thesis, Royal Institute of Technology, Stockholm, Sweden, (2003), 56.

3) M. Amin: J. Mater. Process. Technol., 174 (2006), 155.

4) M. Gonzalez, M. B. Goldschmit, A. P. Assanelli, E. N. Dvorkin and E. F. Berdaguer: Metall. Mater. Trans. B, 34B (2003), 455.

5) M. Hasan and S. H. Seyedein: Can. Metall. Q., 37 (1998), 213

6) S. Louhenkilpi: Mater. Sci. Eng. A, 413-414 (2005), 135.

7) W. Wang, K. Blazek and A. Cramb: Metall. Mater. Trans. B, 39 (2008), 66.

8) P. E. Ramirez-Lopez, P. D. Lee and K. C. Mills: Modeling of Casting, Welding and Advanced Solidification Processes XII, Vancouver, Canada, (2009).

9) J. T. Emi, J. H. Shibata, J. M. Suzuki and J. Cho: ISIJ Int., 38 (1998),
834.

10) M. Suzuki, H. Shibata, T. Emi and J. Cho: ISIJ Int., 38 (1998), 268.

11) K. Spitzer, K. Schwerdtfeger and J. Holzhauser: Steel Res., 70 (1999), 430.

12) C. Santos: Modell. Simul. Mater. Sci. Eng., 13 (2005), 1071.

13) T. Emi, S. Seetharaman and A. Yamauchi: ISIJ Int., 42 (2002), 1084.

14) V. N. Neelakantan, S. Sridhar, K. C. Mills and D. Sichen: Scand. J. Metall., 31 (2002), 191.

15) R. Saraswat, A. B. Fox, K. C. Mills, P. D. Lee and B. Deo: Scand. J. Metall., 33 (2004), 85.

16) Y. Meng and B. G. Thomas: Metall. Mater. Trans. B, 34 (2003), 707.

17) P. E. Ramirez-Lopez, R. D. Morales, R. Sanchez-Perez, L. G. Demedices and P. O. Davila: Metall. Mater. Trans. B, 36 (2005), 787.

18) J. L. Liow, M. Rudman and P. Liovic: ISIJ Int., 41 (2001), 225.

19) P. E. Ramirez-Lopez and R. D. Morales: Ironmaking Steelmaking, 33 (2006), 157.

20) J. U. Brackbill, D. B. Kothe and C. Zemach: J. Comput. Phys., 100 (1992), 335.

21) K. Sorimachi, T. Yamauchi and A. Yamauchi: Ironmaking Steelmaking, 29 (2002), 203.

22) R. D. Morales and P. E. Ramirez-Lopez: AISTech Conf. Proc., Asoc. Iron and Steel Tech. Warrendale, PA, (2006), 1005.

23) P. E. Ramirez-Lopez, P. D. Lee, K. C. Mills, R. D. Morales, A. R. Sanchez-Perez and A. Ramos-Banderas: 6th European Conf. on Continuous Casting, Associazione Italiana di Metallurgia, Riccione, Italy, (2008).

24) R. Carli, C. Carna, F. Magni and A. C. Mapelli: 6th European Conf. on Continuous Casting, Associazione Italiana di Metallurgia, Riccione, Italy, (2008).

25) G. G. Lee, H. Shin, B. G. Thomas, S. Kim, D. Kim and S. Yu: Iron \& Steel Technology Conf., TMS, Warrendale, PA, USA, (2007), 1.

26) A. Badri, T. T. Natarajan, C. C. Snyder, K. D. Powers, F. J. Mannion and A. W. Cramb: Metall. Mater. Trans. B, 36B (2005), 355.

27) A. Badri, T. T. Natarajan, C. C. Snyder, K. D. Powers, F. J. Mannion and A. W. Cramb: Metall. Mater. Trans. B, 36B (2005), 373.

28) A. C. Mapelli, A. W. Nicodemi and A. A. Marcandalli: Ironmaking Steelmaking, 30 (2003), 265.

29) C. Ojeda, J. Sengupta, B. G. Thomas, J. Barco and J. L. Arana: AISTech. Conf. Prog. Asoc. Iron and Steel Tech., Warrendale, PA, (2006), 1017.

30) A. T. Emi, H. Nakato, Y. Iida, K. Emoto, R. Tachibana, T. Imai and H. Bada: 61st National Open Hearth Basic Oxygen Steel Conf. Proc., ISS/AIME, Warrendale, PA, (1978), 350.

31) H. Yamamura, W. Yamada, K. Okazawa and T. Kajitani: ISIJ Int., 46 (2006), 250

32) H. J. Shin, S. H. Kim, B. G. Thomas, G. G. Lee, J. M. Park and J. Sengupta: ISIJ Int., 46 (2006), 1635.

33) E. S. Szekeres: Iron Steel Eng., 73 (1996), 29.

34) J. Sengupta and H. J. Shin: Acta Mater., 54 (2006), 1165.

35) M. Hanao and M. Kawamoto: ISIJ Int., 48 (2008), 180.

36) K.C. Mills and A. B. Fox: ISIJ Int., 43 (2003), 1479.

37) K. Okazawa, T. Kajitani, W. Yamada and H. Yamamura: ISIJ Int., 46 (2006), 234.

38) Y. Meng and B. G. Thomas: Metall. Mater. Trans. B, 34 (2003), 685.

39) A. Yamanaka, M. Kawamoto and M. Hanao: ISIJ Int., 49 (2009), 365 . 